\title{
UM ESTUDO SOBRE A ORGANIZAÇÃO E O DESENVOLVIMENTO DO PROCESSO ORÇAMENTÁRIO EM EMPRESAS DE TECNOLOGIA DE FLORIANÓPOLIS
}

\author{
Francielle Koerich Simas' \\ Alexandre Marino Costa ${ }^{2}$ \\ Gilberto de Oliveira Moritz ${ }^{3}$
}

\begin{abstract}
Resumo
O sistema orçamentário é uma ferramenta administrativa que facilita a integração das atividades através do planejamento e do controle das diversas áreas da organização. Este artigo objetiva identificar a estrutura e os principais métodos utilizados para a elaboração dos orçamentos nas empresas de tecnologia de Florianópolis. A investigação foi realizada através de uma pesquisa exploratória, descritiva, bibliográfica e quantitativa. Os dados foram coletados por meio de um questionário com perguntas fechadas dirigidas a uma população composta por 24 empresas do ramo de tecnologia, de Florianópolis, cadastradas pela Federação das Indústrias do Estado de Santa Catarina - FIESC. Observou-se que a maioria das empresas ainda não apresenta a estrutura de sistema orçamentário sistematizada, na qual são projetadas todas as peças orçamentárias pertencentes aos processos organizacionais. Pode-se destacar também que o principal método de projeção dos itens considerados para elaboração das peças orçamentárias é constituído pelo reajuste dos dados históricos. Constatou-se que a participação na decisão de elaboração do orçamento é formada em sua maioria pela alta administração e que os recursos tecnológicos utilizados para o desenvolvimento dos orçamentos são compostos, principalmente, por planilhas eletrônicas.
\end{abstract}

Palavras-chave: Elaboração do orçamento. Administração financeira. Prática do orçamento nas empresas de tecnologia.

' Graduada em Administração. Endereço: Universidade Federal de Santa Catarina, Centro Sócio-Econômico, Departamento de Ciências da Administração, Campus Universitário, Trindade, Florianópolis, SC. CEP: 88040-900. E-mail: francielleks@yahoo.com.br.

${ }^{2}$ Doutor em Engenharia de Produção pela Universidade Federal de Santa Catarina - UFSC. Professor Adjunto do Departamento de Ciências da Administração da Universidade Federal de Santa Catarina - UFSC. Endereço: Universidade Federal de Santa Catarina, Centro Sócio-Econômico, Departamento de Ciências da Administração, Campus Universitário, Trindade, Florianópolis, SC. CEP: 88040-900. E-mail: marino@cse.ufsc.br.

${ }^{3}$ Doutor em Engenharia de Produção pela Universidade Federal de Santa Catarina - UFSC. Professor Titular do Departamento de Ciências da Administração da Universidade Federal de Santa Catarina - UFSC. Endereço: Universidade Federal de Santa Catarina, Centro Sócio-Econômico, Departamento de Ciências da Administração, Campus Universitário, Trindade, Florianópolis, SC. CEP: 88040-900. E-mail: gomoritz@cse.ufsc.br. Artigo recebido em: 12/04/2008. Aceito em: 20/05/2008. Membro do Corpo Editorial Científico responsável pelo processo editorial: Prof. João Nilo Linhares. 


\section{INTRODUÇÃO}

As organizações ao redor do mundo e, por conseguinte, as empresas brasileiras estão vivenciando um momento em que o grande desafio é conseguir dominar e conviver com as constantes mudanças. Dentro do contexto atual, as organizações vêm enfrentando um ambiente turbulento e para que sobrevivam faz-se necessária a busca constante por melhorias de desempenho de suas atividades. Para tanto é fundamental o planejamento e o controle dos processos operacionais através da definição de metas e objetivos claros que prospectem a direção das ações futuras, considerando as particularidades da organização e a intenção de crescimento estratégico.

Tais mudanças ainda provocam o aumento da complexidade da administração das atividades organizacionais e passam a exigir das empresas uma maior quantidade de informações para controlar seus processos e tomar decisões estrategicamente. Nesse sentido, o sistema financeiro e a utilização de orçamentos podem ser instrumentos que auxiliam o processo de administração dos recursos e as capacidades organizacionais.

Desse modo, com a implementação de orçamentos é possível a visualização antecipada dos possíveis resultados operacionais, tornando mais precisa a tomada de decisão ao considerar detalhadamente todos os aspectos relevantes para o desenvolvimento das atividades com base na estratégia, além de fornecer informações para o controle dos processos organizacionais. Portanto, através do processo orçamentário as organizações tenderão a alcançar os resultados pré-estabelecidos e a aumentar o seu desempenho.

Desse modo, o presente trabalho tem como objetivo a investigação sobre a forma de elaboração do orçamento nas empresas de tecnologia de Florianópolis, que possuem como principal produto o desenvolvimento de software. Para tanto, neste capítulo são apresentados os itens que se relacionam ao tema problema, os objetivos geral e específicos, a justificativa que motivou este estudo, bem como a estrutura do trabalho.

Com a abertura da economia nacional na década de 1990, as empresas brasileiras foram obrigadas a repensar suas práticas, tornando-se mais eficientes para poder concorrer com empresas internacionais, cuja profissionalização e organização já estavam adaptadas ao mercado competitivo.

Até a década de 1980 o mercado nacional, acostumado com a reserva de mercado, determinava o preço de seus produtos de dentro para fora. Com o novo cenário passou a ditar os preços e as empresas, para se tornarem competitivas, tiveram que adequar seus custos para poder obter lucros.

Diante dessas mudanças a prática de projeção das atividades operacionais das organizações como vendas, compras, produção, recursos humanos e finanças devem 
Um estudo sobre a organização e o desenvolvimento do processo orçamentário em empresas de tecnologia...

ser cada vez mais precisas para demonstrar o futuro mais provável, visando alcançar resultados e eficiência no desempenho organizacional.

Nesse sentido, o planejamento e o controle das atividades empresariais tornam-se imprescindíveis para que sejam atingidos os objetivos estratégicos e a participação no mercado seja crescente. Portanto, é essencial destacar a importância da administração financeira, haja vista que, independente do porte da empresa, isso é fundamental para a sua manutenção e seu desenvolvimento.

Com o objetivo de integrar, planejar e controlar suas atividades e minimizar as ansiedades do futuro, muitas empresas estão utilizando os orçamentos tratando, assim, de modo mais eficiente e completo a sua administração financeira.

No entanto, muitas empresas ainda utilizam a intuição e o improviso com a expectativa de atingir seus objetivos, conforme o que foi idealizado. Ainda é uma prática comum a não utilização de métodos estatísticos ou matemáticos em suas projeções e de sistemas de informação em seus processos decisórios.

Esse fato evidencia as dificuldades que as empresas encontram na definição exata de quanto devem vender, a que preço, quais os custos atribuídos a cada produto, quanto são as despesas operacionais e de quanto será o lucro para o ano seguinte. Algumas delas nem sequer descrevem sua intenção de crescer ou em quanto pretendem aumentar a sua participação no mercado.

Entretanto, para as empresas se destacarem neste ambiente competitivo, objetivando alcançar resultados diferenciados, as atividades operacionais devem ser estruturadas e planejadas de maneira lógica, proporcionando, assim, integração entre as diversas áreas da organização.

Para tanto, a utilização do processo orçamentário pode ser considerada uma alternativa para a estruturação do planejamento e controle das atividades na qual são determinadas as projeções de vendas, produção, custos, despesas, servindo como uma ferramenta para auxiliar a tomada de decisão estratégica e o desempenho organizacional.

O sistema orçamentário é uma das condições essenciais para o sucesso empresarial na medida em que permite que a empresa visualize com antecipação as atividades que serão desempenhadas no período projetado, bem como o caminho a ser percorrido.

Por estar inserido neste ambiente de alta competitividade, não se admite mais improvisação. Em especial as empresas de tecnologia que trabalham em um ambiente em que a concorrência é fator determinante para o desenvolvimento e o crescimento organizacional. Nesse sentido, as empresas que optarem pela utilização de orçamentos para auxiliar no processo de administração devem elaborá-los de modo a considerar as particularidades, os recursos e as limitações de cada empresa. 
No entanto, é fato que a utilização de métodos apropriados para a projeção é fundamental para o funcionamento e alcance dos objetivos propostos pelo orçamento, conforme estabelecidos pelas estratégias da organização. Além disso, destaca-se que a forma como a ferramenta é utilizada contribui para a sua eficiência.

Dessa forma, considerando os argumentos acima descritos este trabalho apresenta a seguinte pergunta de pesquisa: Quais são os métodos e estruturas organizacionais adotados pelas empresas de tecnologia de Florianópolis para a elaboração de seus orçamentos?

Diante do questionamento acima, este trabalho objetiva identificar a estrutura e os métodos utilizados para a elaboração do sistema orçamentário das empresas do ramo de tecnologia de Florianópolis que possuem como principal produto o desenvolvimento de software.

Verifica-se que no cenário das pequenas e médias empresas ainda é dada pouca relevância às propostas de implementação de métodos e ferramentas que objetivam melhorar o desempenho e a eficiência empresarial. No que se refere ao tema orçamentos, percebe-se a dificuldade que as empresas têm em desenvolver um plano orçamentário, devido à pouca profissionalização de seus administradores, bem como devido às mudanças constantes no processo operacional e aos aspectos culturais fortemente enraizados em suas estruturas organizacionais (ZDANOVIWZ, 2003).

Ante essa situação, não há mais espaço para improvisação. Sendo assim, a estruturação de um sistema orçamentário pode sim eliminar as ansiedades do futuro, através do planejamento e do controle de todas as atividades, além de proporcionar rendimentos acima da média para a organização.

Contudo, a utilização da ferramenta em si não é solução. A forma como tudo é estruturado será fundamental para a otimização do resultado. Assim, o presente estudo tem como tema o orçamento e possui a intenção de investigar como ele é elaborado nas empresas do ramo de tecnologia de Florianópolis.

\section{FUNDAMENTAÇÃO TEÓRICA}

Inicialmente, neste artigo, será caracterizado o planejamento orçamentário, bem como a sua importância para a realização do orçamento. Na seqüência serão abordadas as definições e finalidades do uso do orçamento para as empresas. Em seguida, são apresentados os tipos de orçamentos operacionais, sendo eles: orçamento de venda, orçamento de produção, orçamento de despesas operacionais, orçamento de caixa, orçamento de investimentos, demonstrativo de resultado do exercício projetado e o balanço patrimonial projetado. Por fim, são destacadas as vantagens e limitações do uso do orçamento e a importância do controle para o processo orçamentário. 
Um estudo sobre a organização e o desenvolvimento do processo orçamentário em empresas de tecnologia...

\subsection{Planejamento Orçamentário}

Para alcançar a vantagem competitiva, as organizações devem ser administradas por gestores que tenham a capacidade de obter informações no mercado e na própria empresa para assim formular estratégias fundamentadas nos objetivos organizacionais e que direcionem as tomadas de decisões mais acertadas.

Stoner e Freman $(1999$, p. 5) afirmam que "ato de administrar trata-se do processo de planejar, organizar, liderar e controlar os esforços realizados pelos membros da organização e o uso de todos os outros recursos organizacionais para alcançar os objetivos estabelecidos."

Por outro lado, Zdanowicz (2003, p. 131) defende que

[...] planejar significa refletir sobre as experiências passadas e a realidade presente, definindo primeiro o posicionamento futuro da empresa, considerando o alinhamento neste processo das variáveis estratégicas: econômicas, financeiras, sociais e políticas.

Sendo assim, o planejamento visa à definição dos objetivos a serem atingidos e a posterior escolha da melhor alternativa, levando em conta as informações do ambiente em que a empresa está inserida.

Segundo Zdanowicz (2003), os principais elementos do planejamento são as diretrizes, as premissas, os objetivos, as metas e as estratégias. As diretrizes representam os fins de sua existência e as idéias globais que estruturam o planejamento. As premissas correspondem às hipóteses básicas que afetam o curso de implementação das estratégias. Os objetivos são definidos como os resultados que se espera obter. As metas são exatamente a quantificação dos objetivos previamente definidos. As estratégias referem-se às alternativas de direção e aos esforços necessários para que se alcancem os objetivos e as metas preestabelecidos.

\subsection{Orçamentos}

O orçamento é uma ferramenta que desempenha papel importante na gestão dos recursos organizacionais, além de ser um importante instrumento de planejamento e controle. Segundo Brookson (2001), os orçamentos auxiliam na coordenação das atividades dos líderes de diferentes setores, são alinhados com os objetivos organizacionais, imputam autoridade ao gerente de cada área para fazer desembolsos e estabelecem metas claras de receitas.

A utilização do plano orçamentário permite a empresa definir padrões, normas e preceitos que servirão de base para a elaboração e execução das atividades organizacionais. Através da análise do comportamento das variáveis que compõem o 
orçamento e o confronto destas com os cenários atuais é que são possíveis as projeções das perspectivas futuras. Essa perspectiva é potencializada pela tecnologia de informação, principalmente por meio de planilhas eletrônicas (LENNING, 2000).

O orçamento é um instrumento que tem o objetivo de otimizar o rendimento dos recursos da empresa, sejam eles físicos ou monetários. Corroborando com esta afirmativa Zdanowicz (2000, p. 22) diz que o orçamento "é o instrumento utilizado para elaborar, de forma eficaz e eficiente, o planejamento e controle financeiro das atividades operacionais e de capital da empresa, auxiliando a tomada de decisão".

Contudo, para que esse instrumento de planejamento e controle seja eficaz é necessário que apresente algumas características, tais como: flexibilidade na aplicação, adequação aos novos cenários, metas fixadas claramente para todos os níveis, critérios definidos uniformemente e participação direta dos responsáveis (ZDANOWICZ, 2000).

Assim, o orçamento pode ser considerado como um desafio para a organização com a proposta de realizar suas atividades de modo planejado, organizado e coordenado para que as metas sejam atingidas. Contudo, tal ferramenta não pode subjugar o planejamento empresarial (HOPE; FRASER, 2003).

Para a mensuração quantitativa e econômica dos planos organizacionais, faz-se necessário a utilização de técnicas de previsões que podem variar de empresa para empresa, dependendo de sua estrutura. Algumas empresas preferem aderir ao modelo mais participativo, outras, porém, ao modelo mais centralizador. O modelo participativo permite maior comprometimento da equipe, porém destaca-se que a alta administração deve ter a autonomia de intervir no processo realizando ajustes necessários. Desse modo, o orçamento deve ser visto como um instrumento inerente à cultura organizacional. Segundo Padoveze (2006, p. 233) "quando o modelo é bem formatado e conduzido, aderente à cultura geral da organização os resultados tendem a ser expressivos".

De acordo com Padoveze (2006), a organização do orçamento deve compreender: o comitê orçamentário, as premissas orçamentárias, o modelo do processo orçamentário, a estrutura contábil, um sistema de apoio, os relatórios/cronogramas e a análise de cenários.

Este último é um dos fatores-chave para a definição das estimativas orçamentárias. $\mathrm{O}$ entendimento do ambiente interno e externo, bem como de suas tendências, facilitará a formalização de um plano orçamentário mais próximo da realidade e que direcione para a tomada de decisão ótima. De acordo com Padoveze (2006, p. 239), "as informações geradas constantes no cenário tido como probabilisticamente o mais provável deverão ser assumidas para direcionar as premissas do plano orçamentário para o próximo período".

Uma prática muito comum, quando da definição de estimativas orçamentárias, é a utilização de dados passados para a projeção futura. Esse método pode trazer 
Um estudo sobre a organização e o desenvolvimento do processo orçamentário em empresas de tecnologia...

bons resultados, visto que há forte tendência de os eventos se reproduzirem, porém, a combinação de elementos novos deve ser também considerada. Alguns gestores discordam de que os dados passados possam contribuir para a estimação de metas futuras e acabam por utilizar o orçamento denominado "base zero".

Este modelo consiste na estruturação de um orçamento que nunca parte da observação de dados anteriores, com a justificativa de que tais dados podem conter erros e acabar por perpetuar para as futuras metas. Segundo Padoveze (2005, p 42), "a proposta do orçamento base zero está em rediscutir toda a empresa sempre que se elabora um orçamento. Está em questionar cada gasto, cada estrutura, buscando verificar sua real necessidade".

De acordo com Padoveze (2005), o orçamento tem o propósito de ser um canal de comunicação e coordenação, instrumento de motivação, avaliação e controle, além de fonte de informações para a tomada de decisão.

Para a elaboração do orçamento, a organização define metas a serem cumpridas pelos setores. Porém, devido às diferenças entre os resultados obtidos e os orçados muitas empresas estão adotando o chamado orçamento variável. Esse tipo de orçamento expressa as relações das alterações dos valores das despesas influenciadas pelas mudanças de volumes de produção ou atividades. Nesse sentido, Welsch (1996, p. 193) considera tais orçamentos "como orçamentos dinâmicos porque as estimativas de despesas para qualquer volume ou ritmo de atividade podem ser rapidamente calculadas".

Após a definição da estrutura a ser utilizada pela empresa, segue o momento da instalação do sistema. Este, porém pode causar certa rejeição por parte das pessoas que tendem ao conservadorismo e resistem às mudanças. Outro fator que pode vir a dificultar o processo de implementação é o mau uso desta ferramenta de planejamento e controle, podendo, assim, gerar a percepção de que sua elaboração requer muito tempo e esforço por parte dos gestores. Desse modo, Welsch (1996) salienta que a introdução do plano orçamentário deve ser cuidadosamente planejada, avaliando-se minuciosamente todas as varáveis envolvidas no processo.

\subsubsection{Orçamento de Vendas}

$\mathrm{O}$ orçamento de vendas evidencia a expectativa da empresa, em relação às vendas dos produtos que comercializa, apontando o preço unitário e as quantidades, gerando, assim, o valor total da receita que se espera auferir.

No plano geral de operações da empresa, o orçamento de vendas é muito relevante e deve ser planejado com seriedade e cautela, visto que a estimativa de vendas será fundamental para o restante do processo. Segundo Welsch (1996, p. 95), “o plano de vendas é o alicerce do planejamento periódico da empresa, pois praticamente todo o restante do planejamento da empresa baseia-se nas estimativas de vendas". 
Assim, sua importância é destacada por Zdanowicz (2000, p. 33), visto que "representa papel significativo dentro do sistema de planejamento financeiro devido a sua interdependência com as outras áreas da empresa”.

Para a definição da projeção das quantidades vendidas, faz-se necessário o estabelecimento de quais serão os métodos utilizados para a sua estimação e, conseqüentemente, deve-se trabalhar com informações precisas e claras. De acordo com Sanvicente e Santos (2000, p. 44), "a dificuldade que se encontra nessa análise é decorrente, muitas vezes, da carência de informações necessárias e da impossibilidade de quantificação de algumas dessas variáveis".

Através do método da concorrência são feitas análises da relação de preços e participação no mercado, praticadas no passado, e dos preços alcançados pelos concorrentes, definindo a precificação dos produtos/serviços na conjuntura atual. Com o método $d u$ pont determina-se a taxa de retorno sobre o investimento, considerando as vendas desejadas para o período orçado, mais os custos unitários projetados e as despesas.

\subsubsection{Orçamento de Produção}

Na elaboração da programação da produção é fundamental que o planejamento do orçamento de produção esteja detalhado com informações precisas de materiais e mão-de-obra necessários, bem como instrução sobre a capacidade instalada e logística disponível. Para tanto, o orçamento de produção é quantitativo e deverá ser expresso em termos de unidades físicas a serem produzidas (PADOVEZE, 2005).

De acordo com Zdanowicz (2003, p. 154), o orçamento de produção determinará "as quantidades de produtos que deverão ser fabricados, tendo em vista o volume de vendas projetado e a política fixada para estoques de produtos prontos e em processamento, projetando os custos e as despesas relacionadas diretamente com o processo produtivo". É a partir do orçamento de produção que serão definidas as quantidades de matérias-primas, mão-de-obra direta e as despesas indiretas de fabricação. Sendo assim, o orçamento de matérias-primas deve estar relacionado com a estratégia da empresa e alinhado a todas as atividades produtivas da empresa, sendo necessário o cumprimento das etapas de projeção de quantidades de matérias-primas, fixação da política de estoques e determinação do custo estimado de matérias-primas.

Portanto, para que a empresa maximize os resultados globais, a alta administração deve planejar com responsabilidade as políticas de estoque, visto que esta se relaciona com todas as áreas funcionais da empresa - compras, produção, vendas e finanças - que possuem interesses conflitantes e que devem ser administradas (SANVICENTE; SANTOS, 2000).

Para a preparação do orçamento de mão-de-obra é preciso o fornecimento de informações referentes ao volume necessário de mão-de-obra direta, tais como: o 
Um estudo sobre a organização e o desenvolvimento do processo orçamentário em empresas de tecnologia...

número de empregados exigidos, o custo unitário de fabricação de cada produto, a projeção do salário médio da hora trabalhada e o custo final da mão-de-obra direta, juntamente com os encargos sociais.

O papel fundamental do orçamento de mão-de-obra direta é a estimação do número de funcionários necessários para a produção e projeção das taxas médias de remuneração/encargos sociais. Segundo Padoveze (2005, p. 82), "a capacidade da mão-de-obra normalmente é medida em horas necessárias para os processos, ou em relação às quantidades de produtos ou serviços intermediários ou finais". Portanto, o orçamento de produção é peça fundamental para que a empresa ofereça produtos de qualidade a custos competitivos, considerando os aspectos abordados como matériaprima, mão-de-obra direta e despesas indiretas de fabricação.

\subsubsection{Orçamento de Despesas Operacionais}

O orçamento de despesas é a parte mais trabalhosa do processo, visto que há uma grande variedade de tipos de despesas a serem consideradas e é necessário elaborar pelo menos uma peça orçamentária para cada setor da empresa. Segundo Welsch (1996, p. 177) “o planejamento de despesas deverá envolver todos os níveis administrativos para que o orçamento de despesas realistas possa ser elaborado para cada departamento, divisão ou qualquer outra unidade administrativa superior".

Um dos objetivos do orçamento de despesas é a identificação dos itens que irão representar as saídas de caixa futuras e o controle efetivo dos custos. Ao se fazer o levantamento das despesas do período pretende-se também analisar quais destes itens poderão ser reduzidos, eliminados ou aumentados, considerando os recursos disponíveis e os objetivos e metas organizacionais (ZDANOWICZ, 2000).

O objetivo principal do orçamento de despesas financeiras será a projeção dos recursos de terceiros, captado ou a captar, descrevendo os valores investidos e os encargos financeiros devidos às instituições que negociaram os empréstimos. Sendo assim, as principais despesas financeiras correspondem aos juros, impostos sobre operações de crédito, taxas de abertura de crédito, atualizações monetárias, avais, fianças, comissões bancárias e taxas de análise e fiscalização de projetos de investimentos (ZDANOWICZ, 2003).

\subsubsection{Orçamento de Caixa}

O orçamento de caixa constitui-se em uma das peças mais importantes para exercer o planejamento e controle financeiro, pois proporciona a identificação com antecedência dos recursos que serão aplicados ou captados pela empresa. Segundo Zdanowicz (2003, p. 168), “o orçamento de caixa é necessário para a empresa esta- 
belecer o equilíbrio financeiro entre as entradas e saídas futuras, efetuando, assim, o seu planejamento e controle financeiros de curto e médio prazos".

Em síntese o orçamento de capital é fundamental no sentido em que aponta a futura situação da empresa e projeta possíveis aplicações e captações de recursos, ou seja, este se constitui em uma ferramenta básica para o planejamento e controle financeiro da empresa (ZDANOWICZ, 2003).

\subsubsection{Orçamento de Investimentos}

O orçamento de investimentos deve ser preparado com base nos planos e políticas de caráter amplo, envolvendo o planejamento de longo prazo, bem como a posição financeira e de caixa necessária ou desejada para o futuro da organização (WELSCH, 1996).

As principais técnicas de mensuração do retorno sobre os investimentos são payback, valor atual líquido e taxa interna de retorno.

Sendo assim, quanto maior a análise antes da efetiva decisão sobre os investimentos, mais retorno financeiro podem ser obtidos, além de evitar erros na escolha de projetos importantes para a organização, visto que uma vez tomada a decisão, não será facilmente modificada ou revertida (SANVICENTE E SANTOS, 2000).

\subsubsection{Demonstrativo de Resultado do Exercício e Balanço Patrimonial Projetados}

O demonstrativo do resultado confronta os níveis de receitas com os custos e despesas projetados, consolidando os impactos no resultado do período da organização. Segundo Zdanowicz (2000, p. 104)

[...] essa demonstração permitirá visualizar, de forma sintética, todos os instrumentos auxiliares, que comporão o planejamento econômicofinanceiro, ou seja, os orçamentos de vendas, produção e despesas operacionais, bem como o lucro líquido operacional ou prejuízo projetado.

O balanço patrimonial projetado, segundo Franco (1992, p. 39), é “a representação sintética dos elementos que fornecem o patrimônio, evidenciando o diferencial que completa a equação entre seus valores positivos e negativos".

Através do controle do processo orçamentário é possível analisar a lucratividade, verificar os impactos na liquidez e no endividamento, identificar a situação patrimonial e quantificar o desempenho organizacional projetando o valor gerado para a organização (PADOVEZE, 2005).

Para tanto todas as peças orçamentárias devem ser acompanhadas através de informações contidas em relatórios, analisando as variações do ocorrido com as metas 
Um estudo sobre a organização e o desenvolvimento do processo orçamentário em empresas de tecnologia...

orçadas. Sendo assim, Zdanovicz (2003, p. 179) afirma que “o controle orçamentário será a técnica que procurará acompanhar, avaliar e analisar o planejamento em suas várias etapas, verificando as diferenças e sugerindo medidas preventivas e corretivas para serem implementadas".

\section{METODOLOGIA}

Para que o objetivo seja alcançado toda pesquisa adota métodos previamente planejados. Portanto, este estudo foi definido como uma pesquisa exploratória, descritiva, bibliográfica e quantitativa.

A pesquisa exploratória caracteriza-se como a fase preliminar do estudo que antecede o planejamento formal do trabalho, possibilitando a elaboração da avaliação e da viabilidade de desenvolvimento do trabalho, bem como do estabelecimento de critérios, métodos e técnicas a serem adotados (ANDRADE, 2004).

Para Acevedo e Nohara (2004, p. 51), o principal objetivo da pesquisa exploratória é "proporcionar maior compreensão do fenômeno que está sendo investigado, permitindo assim que o pesquisador delineie de forma mais precisa o problema".

A pesquisa descritiva tem como objetivo o conhecimento da realidade dos fatos, bem como a definição de suas características e problemas, sem, no entanto, vir a explicar o fenômeno em estudo. Segundo Acevedo e Nohara (2004, p. 51), este tipo de pesquisa visa "descrever o fenômeno estudado ou as características de um grupo, bem como compreender as relações entre os conceitos envolvidos no fenômeno em questão".

Esta pesquisa pode ser classificada como exploratória no sentido desse objetivar a obtenção de maior familiaridade com o problema, com vistas a torná-lo mais explícito e ainda estabelecer critérios do estudo pretendido; e descritiva, visto que tem por finalidade a descrição das características da população estudada, assim como o estabelecimento das relações entre as variáveis.

Segundo Fachin (2003), a pesquisa bibliográfica tem como objetivo principal a seleção e organização de tópicos de interesse para auxiliar no seu desenvolvimento.

Este estudo propõe uma abordagem quantitativa, na medida em que envolve a mensuração e quantificação das respostas dadas em cada pergunta do questionário aplicado, através das informações fornecidas pelas empresas pesquisadas. Conforme Chizzotti (2001), este tipo de pesquisa pode ser considerado mais aprofundado, visto que prevê a mensuração de variáveis pré-estabelecidas, procurando verificar e explicar sua influência sobre outras variáveis, mediante a análise da freqüência de incidências e de correlações estatísticas, sendo que o pesquisador descreve, explica e prediz.

Decidido o tipo de pesquisa, o passo seguinte foi definir o universo de pesquisa. De acordo com Vergara (2007), o universo de pesquisa é formado pelo conjunto de elementos que possuem características abordadas no objetivo do estudo. 
Sendo assim, o universo de pesquisa do presente trabalho compreende as empresas de tecnologia de Florianópolis que desenvolvem software. A população de estudo, portanto, é composta por 24 empresas do ramo de tecnologia estabelecidas em Florianópolis que possuem cadastro na instituição FIESC, cujos produtos principais são o desenvolvimento de softwares.

Essa escolha foi incentivada pelo fornecimento de dados atualizados das empresas pertencentes ao universo de pesquisa, através de uma busca no banco de dados da instituição FIESC com as palavras-chave: tecnologia, Florianópolis e software.

Para a elaboração deste trabalho foram utilizadas tanto fontes primárias como secundárias. Como fonte primária foram obtidos dados através de questionários enviados por e-mail para as empresas pertencentes à população de pesquisa definida, e como dados secundários estão compreendidos o levantamento bibliográfico, dissertações, monografias e pesquisas na Internet.

Neste trabalho utilizou-se como método para a coleta de dados o questionário de forma estruturada com perguntas pré-definidas e fechadas. Essa escolha pode ser explicada pelo fato de se pretender obter maior conhecimento sobre as práticas e métodos utilizados na elaboração de orçamentos nas empresas de tecnologia de Florianópolis.

Para tanto, o questionário foi elaborado com 28 perguntas relacionadas ao objetivo, e enviado por e-mail para a população já delimitada. Anteriormente ao envio, foram realizadas ligações telefônicas para as empresas com o intuito de obter informações sobre o nome da pessoa responsável que poderia responder ao questionário, sendo então enviado por e-mail aos seus cuidados.

O período da coleta de dados ocorreu a partir do dia 14 de setembro de 2007 e estendeu-se até o dia 17 de outubro do mesmo ano, data em que foi reenviado o último e-mail respondido. A taxa de retorno dos questionários foi de 58\%, que representa 14 empresas, e a principal razão de não-resposta foi descrita como "a falta de tempo devido à quantidade de serviços na empresa". Das 10 empresas que não responderam o questionário, $20 \%$ simplesmente não deram explicações e com as demais foram realizados contatos telefônicos, mas também argumentaram que não poderiam responder.

\section{APRESENTAÇÃO E ANÁLISE DOS RESULTADOS}

Neste item buscou-se identificar as características da organização, bem como a estrutura do planejamento estratégico através da descrição do tamanho da empresa, formação da diretoria, elaboração e estrutura do plano estratégico, itens importantes para o desenvolvimento e identificação de áreas que possuem políticas bem definidas. 
Um estudo sobre a organização e o desenvolvimento do processo orçamentário em empresas de tecnologia...

\subsection{Tamanho da Empresa}

Através desta questão a pesquisa investigou o tamanho das organizações e pode classificá-las em micro, pequena, média e grande empresa.

\begin{tabular}{|c|c|c|}
\hline Itens & Freqüência Absoluta & Freqüência Relativa \\
\hline Média & 7 & $50 \%$ \\
\hline Micro & 5 & $36 \%$ \\
\hline Pequena & 2 & $14 \%$ \\
\hline Grande & 0 & $0 \%$ \\
\hline Total & 14 & $100 \%$ \\
\hline
\end{tabular}

Tabela 1 - Porte da empresa

Fonte: Dados primários

Como apresentado na Tabela 1, 50\% das empresas respondentes correspondem às empresas de médio porte, não havendo nenhuma empresa classificada como de grande porte. A população também é composta por $36 \%$ de microempresas e $14 \%$ de empresas de pequeno porte.

Esse resultado demonstra que as empresas respondentes possuem um perfil contrastante e suas estruturas são compreendidas por um número maior de funcionários com possibilidade de administração mais profissional.

\subsection{Formação da Diretoria}

Nesta questão, a pesquisa descreveu a formação da diretoria, sendo este item classificado em familiar, profissional, mista e outros.

\begin{tabular}{|c|c|c|}
\hline Itens & Freqüência Abs. & Freqüência Relativa \\
\hline Profissional & 12 & $86 \%$ \\
\hline Familiar & 2 & $14 \%$ \\
\hline Mista & 0 & $0 \%$ \\
\hline Outros & 0 & $0 \%$ \\
\hline Total & 14 & $100 \%$ \\
\hline
\end{tabular}

Tabela 2 - Formação da diretoria

Fonte: Dados primários 
Depois de analisada a formação da diretoria, notou-se que a grande maioria, $86 \%$, das empresas são constituídas por administrações profissionais, sendo apenas $14 \%$ com base familiar e nenhuma com formação mista.

Através desse resultado, pode-se dizer que há forte tendência de que estas empresas realizem esforços no sentido de planejar e controlar os seus processos de modo mais estruturado, visto que existe o predomínio de profissionais no desenvolvimento de sua administração.

\subsection{Síntese dos Resultados da Pesquisa}

A presente pesquisa investigou a estrutura e os principais métodos utilizados na elaboração dos orçamentos das empresas de tecnologia de Florianópolis, e com isso destaca-se a síntese dos principais resultados deste estudo.

Com relação ao porte das empresas pesquisadas, percebeu-se que 50\% delas correspondem a médio porte, enquanto que $36 \%$ são formadas por microempresas. Quanto à formação da diretoria, $86 \%$ são compostas por administração profissional.

É possível verificar que $14 \%$ das empresas não elaboram o plano estratégico e dos $86 \%$ que elaboram o planejamento estratégico, $50 \%$ o formulam de modo informal. Quando relacionado o porte das empresas e a estrutura do plano estratégico, identificouse que das médias empresas, $72 \%$ apresentam estrutura formal e $28 \%$ informal.

Nota-se, ainda, que dos três principais itens considerados mais importantes na elaboração do plano estratégico, destacam-se o mercado consumidor com $71 \%$, a capacidade produtiva com $50 \%$ e os recursos financeiros com $50 \%$. Identificou-se, também, que $71 \%$ das empresas elaboram seus orçamentos e dentro desse percentual, $80 \%$ o formulam para um período anual.

Cabe ressaltar que $50 \%$ das empresas não elaboram os orçamentos e não possuem plano estratégico e das empresas que não elaboram o orçamento, $50 \%$ são de porte médio e $50 \%$ de microporte.

Destaca-se como principal motivo da não-elaboração dos orçamentos o tempo necessário para a sua elaboração representando $75 \%$ das respostas. Quanto às empresas que elaboram o orçamento, $100 \%$ formulam metas bem definidas em que $80 \%$ são caracterizadas como flexíveis.

Com relação às questões de elaboração do orçamento e áreas com políticas bem definidas, constata-se que $72 \%$ das empresas, que elaboram o orçamento de vendas, afirmam possuir políticas bem definidas nessas áreas, enquanto que apenas $38 \%$ das empresas que elaboram o orçamento de caixa responderam ter políticas bem definidas para esta área.

Cruzando as respostas das questões "elaboração do orçamento e itens mais importantes para a elaboração do plano estratégico", verificou-se que $75 \%$ das em- 
presas, que elaboram o orçamento de produção, o consideram como um dos três itens mais importantes para atingir seus objetivos. No entanto,as empresas que elaboram o orçamento de investimentos não o consideram como um dos três principais itens para a elaboração do plano estratégico.

Pode-se constatar, quanto ao tipo de sistema utilizado, que apenas $10 \%$ das empresas utilizam softwares desenvolvidos especificamente para a organização, enquanto que as demais utilizam softwares prontos ou planilhas eletrônicas.

Verificou-se, ainda, que os principais responsáveis pela elaboração do orçamento são diretores correspondendo a 50\%. Os proprietários representam $40 \%$ e $30 \%$ são os consultores e o departamento financeiro. Nenhuma das empresas respondeu ser a participação dos funcionários um dos três principais itens responsáveis pela elaboração dos orçamentos. Pode-se identificar que $80 \%$ das empresas possuem políticas bem definidas nas áreas de vendas e apenas 30\% nas áreas de caixa e investimentos.

Sobre as peças orçamentárias, $70 \%$ das empresas responderam elaborar o orçamento de vendas. Cabe ressaltar que $50 \%$ das empresas que elaboram o orçamento de vendas também formulam o orçamento de caixa e $20 \%$ das que planejam o orçamento de vendas, não projetam o orçamento de caixa.

O principal índice financeiro analisado na elaboração do orçamento de vendas foi a taxa de crescimento, representando $71 \%$, o que evidencia a influência da concorrência. A maioria das empresas, $86 \%$ afirmou utilizar a estimativa total de receita para a projeção do orçamento de vendas, e como forma de estimação destas variáveis destacou-se $86 \%$ a opinião da equipe de vendas e os dados passados reajustados. Quanto ao método de determinação de preços evidenciou-se maior porcentagem o método da concorrência com $71 \%$.

Com relação à peça orçamentária de produção, $80 \%$ afirmaram realizar sua elaboração, e quanto à projeção das operações de desenvolvimento de produtos/ serviços, as empresas utilizaram, principalmente, a atividade constante e a produção por nível de vendas, representando respectivamente $50 \%$.

Notou-se, em relação à peça orçamentária de estoque, que $60 \%$ das empresas responderam não elaborar este tipo de orçamento, sendo que $50 \%$ das empresas que projetam o orçamento de estoques utilizam apenas um método para a estimação dessas variáveis. Os principais itens considerados para a estimativa do orçamento de estoque correspondem ao índice de rotação e ao prazo médio de rotação/estoque mínimo, representados por $50 \%$ cada. Ao cruzar as questões sobre a elaboração do orçamento de produção e estoques, percebe-se que $40 \%$ das empresas formulam o orçamento de produção e de estoques e $100 \%$ não projetam o orçamento de produção e não planejam o orçamento de estoques.

É possível constatar, sobre a peça orçamentária de despesas, que 70\% das empresas elaboram esse tipo de orçamento, sendo que $100 \%$ dela realizam a estimativa 
de mão-de-obra direta e indireta e $86 \%$ projetam as despesas departamentais gerais. Quanto ao método de estimação das variáveis, destaca-se o uso de dados passados reajustados, representando $86 \%$.

Pode-se identificar, quanto à peça orçamentária de investimentos, que $40 \%$ afirmaram elaborar tal orçamento, sendo que o principal método de análise das alternativas de investimento foi a taxa de retorno que apresentou $43 \%$. Verifica-se, também, que $80 \%$ das empresas respondentes elaboram o orçamento de caixa e $100 \%$ realizam a projeção dos níveis desejados de caixa.

Destaca-se que $90 \%$ das empresas respondentes elaboram demonstrativos financeiros, sendo que $67 \%$ elaboram o balanço patrimonial e $100 \%$ o demonstrativo de resultado do exercício. É possível observar que 90\% das empresas realizam a análise dos índices financeiros para a avaliação de desempenho, sendo que o índice de lucratividade obteve $100 \%$ das respostas e o índice de liquidez $44 \%$.

Verifica-se que $80 \%$ das empresas apresentam as diferenças entre as metas orçadas e as reais expressas em relatórios e $100 \%$ realizam a análise das diferenças entre as metas, sendo que a maioria, $88 \%$, elabora esse relatório mensalmente.

Por fim, pode-se constatar que $100 \%$ das empresas pesquisadas consideram o orçamento como um instrumento que auxilia no desempenho organizacional e quanto à forma principal em que auxiliam, o desempenho destaca-se com $90 \%$, tornando mais precisa a tomada de decisão e $60 \%$ tornando mais claros o planejamento e controle.

\section{CONSIDERAÇÕES FINAIS}

Com base nos resultados da pesquisa, constatou-se que as empresas pesquisadas elaboram o orçamento com o objetivo de planejar e controlar suas atividades operacionais, no entanto, não apresentam a preocupação de elaboração do sistema orçamentário global, na qual são projetadas todas as peças orçamentárias envolvidas na administração dos processos organizacionais. Verificou-se através da pesquisa que nenhuma das empresas possui o orçamento completo, com o desenho de todas as peças orçamentárias, o que é um requisito fundamental para a análise das variáveis que influenciam a tomada de decisão.

Os itens considerados para a elaboração de cada peça orçamentária são projetados de modo a permitir a estimação das variáveis envolvidas no processo, proporcionando o planejamento e controle das atividades futuras. No entanto, apesar de possuir uma estrutura bem definida, o principal método de estimação utilizado é o reajuste dos dados passados, o que pode provocar certos desvios e variações entre as metas orçadas e as reais, visto que as mudanças do mercado são constantes e cada vez mais diferentes os fatores que influenciam as ações para o alcance das estratégias definidas e o desempenho organizacional. 
Os recursos tecnológicos utilizados pelas empresas pesquisadas em sua maioria não são constituídos de softwares específicos desenvolvidos para as necessidades dessas organizações, mas sim por planilhas eletrônicas e softwares prontos que são mais adequados à realidade de cada organização devido à simplicidade e à acessibilidade desses sistemas informatizados.

Quanto à estrutura responsável pelo orçamento, cabe ressaltar a forte influência da alta administração formada pelos proprietários e diretores nas decisões sobre a aprovação e elaboração do processo orçamentário. É importante ressaltar a falta de participação dos funcionários no desenvolvimento das metas e objetivos do orçamento.

Verificou-se, referente à integração do orçamento e às estratégias empresariais, que essas empresas ainda são constituídas por uma deficiente estrutura de planejamento estratégico que tende a influenciar as metas orçamentárias devido à falta de definição da direção em que se pretende chegar. Isso pode ser evidenciado pela alta porcentagem de estrutura informal do plano estratégico e pela pequena preocupação com a definição de políticas bem definidas para as diversas áreas da organização.

Após a análise dos resultados da pesquisa, recomenda-se a construção de um plano de ação em que sejam levantadas alternativas para otimizar o processo orçamentário sem, no entanto, utilizar expressivos recursos financeiros de cada organização. Sua essência deve estar em mudanças na forma de organização e planejamento das estruturas orçamentárias, sendo elas: construção de um comitê orçamentário, utilização de planilhas eletrônicas, desenvolvimento do orçamento global, processo de educação orçamentária e elaboração de cenários.

Cabe ressaltar que a maioria das empresas que não elabora seus orçamentos foi motivada pelo tempo necessário para a sua projeção e, as empresas que formulam seus orçamentos justificaram que tal instrumento auxilia na avaliação do desempenho organizacional, tornando mais precisa a tomada de decisão, além de mais claro o planejamento e controle. Nesse sentido, é importante destacar que a forma como o orçamento é elaborado influencia no resultado a ser alcançado e, portanto, na melhoria constante do processo orçamentário. Assim como a revisão e a modificação desse processo é fundamental para que sejam planejadas e controladas todas as atividades operacionais de modo eficiente.

As constatações apresentadas neste artigo, ainda que restritas à população estudada, trazem algumas questões que podem vir a ser objeto de novas pesquisas relacionadas à estrutura orçamentária.

Nesse sentido, a abordagem do tema não se encontra de forma alguma esgotada e seria interessante que novas pesquisas fossem realizadas, a fim de ampliar o conhecimento sobre o tema orçamento e a forma como ele é elaborado.

Uma questão que requer um estudo mais profundo refere-se aos métodos de estimação das peças orçamentárias, visando não apenas a identificação dos métodos, mas sim a investigação de características e de como são realizados na prática. 
Outro aspecto relevante consiste no estudo da real eficiência do processo orçamentário com a finalidade de investigar se essa ferramenta administrativa, efetivamente, auxilia o processo de tomada de decisão e se as projeções realizadas estão próximas das metas reais atingidas.

Por fim, uma questão a ser explorada é a investigação sobre um desenho de proposta orçamentária, na qual seriam identificados os métodos mais adequados de estimação, considerando as características do setor escolhido, bem como a estrutura e o sistema de informação mais eficiente para essas empresas.

\title{
A STUDY ON THE ORGANIZATION AND DEVELOPMENT OF THE BUDGETARY PROCESS IN TECHNOLOGY COMPANIES OF FLORIA- NÓPOLIS
}

\begin{abstract}
The budgetary system is an administrative tool that facilitates the activities integration through the planning and control of the organization many areas. This article objectifies to identify the structure and the main methods used for budgets elaboration in the technology companies of Florianópolis. The study was carried through an exploratory, descriptive, bibliographical and quantitative research. The dices were collected by a questionnaire with closed questions directed to a population composed for 24 technology companies of Florianópolis, registered for the Industries Federacy of the State of Santa Catarina - FIESC. It was observed that the majority of the companies do not present the systemize structure of budgetary system, in which are projected all the budgetary parts pertaining to the processes organization. It can also be detached that the main projection method of the considered items for the budgetary parts elaboration is constituted by the historical dices readjustment. It was evidenced that the participation in the budget elaboration decision is formed in its majority for the high administration and that the used technological resources for the budgets development are composed, mainly, for electronic spread sheets.
\end{abstract}

Keywords: Budget elaboration. Financial administration. Budget practice in the technology companies.

\section{REFERÊNCIAS}

ACEVEDO, C. R.; NOHARA, J. J. Monografia no curso de administração: guia completo de conteúdo e forma. São Paulo: Atlas, 2004. 
Um estudo sobre a organização e o desenvolvimento do processo orçamentário em empresas de tecnologia...

ANDRADE, M. A. Como preparar trabalhos de pós-graduação: noções práticas. 6. ed. São Paulo: Atlas, 2004.

BROOKSON, S. Como elaborar orçamentos. 2. ed. São Paulo: Publifolha, 2001.

CHIZZOTTI, A. Pesquisa em ciências humanas e sociais. 5. ed. São Paulo: Cortez, 2001.

FACHIN, O. Fundamentos de metodologia. 4. ed. São Paulo: Atlas, 2003.

FRANCO, H. Estrutura, análise e interpretação de balanços. 15. ed. São Paulo: Atlas, 1992.

HOPE, J., FRASER, R. Who Needs Budgets? Harvard Business Review, Feb. 2003.

LENNING, J. Drilling for information. Journal of Accountancy. New York. Aug. 2000 .

PADOVEZE, C. L. Planejamento orçamentário: texto e exercícios. São Paulo: Pioneira Thomson Learning, 2005.

PADOVEZE, C. L. Administração financeira de empresas multinacionais: abordagem introdutória. São Paulo: Pioneira Thomson Learning, 2006.

SANVICENTE, A. Z. e SANTOS, C. C. Orçamento na administração de empresas: planejamento e controle. São Paulo: Atlas, 2000.

STONER, J. A. F.;FREMANN, R. E. Administração. Rio de Janeiro: LTC, 1999.

VERGARA, S. C. Projetos e relatórios de pesquisa em administração. 9. ed. São Paulo: Atlas, 2007.

ZDANOWICZ, J. E. Planejamento financeiro e orçamento. Porto Alegra: Sagra, 2000.

ZDANOWICZ, J. E. Criando valor através do orçamento: um modelo de proposta orçamentária global como requisito de sucesso na administração das empresas coureiro-calçadistas do Rio Grande do Sul. Porto Alegre: Novak Multimedia, 2003.

WELSCH, G. A. Orçamento empresarial. 4. ed. São Paulo: Atlas, 1996. 


\section{Apêndice A - Instrumento de Coleta de Dados}

Nome da empresa:

Entrevistado:

Cargo:

Tamanho da empresa: ( ) Micro ( ) Pequena ( ) Média ( ) Grande

Diretoria: ( ) Familiar ( ) Profissional ( ) Mista ( ) Outra:

1 - A empresa elabora o seu plano estratégico, definindo metas e objetivos claros?

( ) Sim ( ) Não Se sim, de que modo? ( ) Formal ( ) Informal

2 - Na elaboração do plano estratégico quais dos itens abaixo a empresa julga mais importantes na definição da estratégia? (assinale no máximo 3)

( ) Conjuntura econômica ( ) Mercado consumidor ( ) Capacidade produtiva

( ) Fornecedores ( ) Despesas ( ) Investimentos ( ) Recursos Financeiros

3 - O orçamento é realizado pela empresa?

( ) Sim Se sim, para que período? ( ) Mensal ( ) Trimestral ( ) Semestral

( )Anual

( ) Não - (então encerra-se o questionário)

4 - As metas orçamentárias da empresa são: (assinale somente 1 alternativa)

( ) Fixas ( ) Flexíveis ( ) Não possuem metas definidas ( ) Outros:

5 - A empresa utiliza a informática para elaborar orçamentos?

( ) Sim ( ) Não Se sim, que tipo de sistema? (assinale uma ou mais alternativas) ( ) Planilhas eletrônicas ( ) Softwares prontos ( ) Softwares desenvolvidos para a empresa ( ) Outros:

6 - Quais os principais responsáveis pela elaboração do orçamento na sua empresa? (assinale no máximo 3)

( ) Diretores ( ) Comitê orçamentário ( ) Proprietários ( ) Gerentes de cada setor ( ) Consultores ( ) Depto financeiro ( ) Todos funcionários ( ) Outros:

7 - A empresa possui políticas bem definidas nas áreas de: (assinale uma ou mais alternativas)

( ) Venda ( ) Despesas departamentais ( ) Produção ( ) Investimentos

( ) Materiais/Estoques ( ) Caixa ( ) Outros: 
Um estudo sobre a organização e o desenvolvimento do processo orçamentário em empresas de tecnologia...

8 - A empresa realiza o orçamento de vendas:

( ) $\operatorname{Sim}$ ( ) Não - (então pule para a questão 13)

9- Quais os índices econômicos abaixo são considerados para a elaboração do orçamento de vendas? (assinale uma ou mais alternativas)

( ) Renda per capita ( ) Taxa de juros ( )Taxa de crescimento do setor

( ) Inflação ( ) Taxa de cambio ( ) Outros:

( ) PIB ( ) Taxa de desemprego

10 - Na definição do orçamento de vendas a empresa realiza: (assinale uma ou mais alternativas)

( ) Estimativa de quantidade de venda por produto ( ) Estimativa de quantidade de venda por mercado ( ) Estimativa de preço de venda ( ) Estimativa total de receita ( ) Estimativa de imposto sobre a venda ( ) Outros:

11 - Na definição da quantidade total de venda são utilizados: (assinale uma ou mais alternativas)

( ) Opinião das equipes de venda ( ) Opinião dos diretores ( ) Estudos de mercado (intenção de compra dos consumidores) ( ) Cálculos estatísticos (média, desvio padrão, regressão linear, etc.) ( ) Dados passados reajustados

( ) Outros:

12 - Na determinação dos preços de venda o principal método utilizado pela empresa é o: (assinale uma ou mais alternativas)

( ) Método de custo - (porcentagem sobre o custo do produto) ( ) Método da concorrência - (pesquisa de preço praticados no mercado) ( ) Método de Du Pont - (Estabelecimento de uma taxa de retorno sobre o investimento) ( ) Outros:

13 - A empresa realiza o orçamento de produção (operações que envolvem o desenvolvimento do produto/serviço)?:

( ) Sim ( ) Não - (então pule para a questão 15)

14 - Na projeção das operações de desenvolvimento do produto/serviço a empresa utiliza principalmente o processo de: (assinale somente 1 alternativa)

( ) Atividade constante (independente da quantidade vendida) ( ) Produção por nível de venda (dependendo do volume de pedidos) ( ) Produção por ciclos (produção de um certo tipo de produto por um período constante) ( ) Outros: 
15- A empresa realiza o orçamento de estoques/materiais?

( ) Sim ( ) Não - (então pule para a questão 17)

16 - Para a elaboração do orçamento de estoque são utilizados: (assinale uma ou mais alternativas)

( ) Índice de rotação de estoques ( ) Estoque médio ( ) Prazo médio de rotação

( ) Estoque máximo ( ) Estoque mínimo ( ) Estoque de segurança

17- A empresa realiza o orçamento de despesas departamentais?

( ) $\operatorname{Sim}$ ( ) Não - (então pule para a questão 20)

18 - Quais dos itens abaixo são considerados na elaboração do orçamento de despesas da empresa? (assinale uma ou mais alternativas)

( ) Mão-de-obra direta e indireta ( ) Consumo de materiais indiretos

( ) Despesas gerais departamentais ( ) Depreciações e amortizações departamentais

( ) Outros:

19 - Na definição do orçamento de despesas o principal método utilizado pela empresa é: (assinale somente 1 alternativa):

( ) Métodos estatísticos ( ) Opinião dos diretores/responsáveis pelo setor

( ) Dados passados reajustados ( ) Outros:

20 - A empresa realiza o orçamento de investimentos?

( ) Sim ( ) Não - (então pule para a questão 22)

21 - No orçamento de investimentos quais os métodos utilizados para a análise das alternativas de investimentos? (assinale uma ou mais alternativas)

( ) Payback ( ) TIR ( ) VPL ( ) Outros:

22 - A empresa realiza o orçamento de caixa?

( ) Sim ( ) Não - (então pule para a questão 24)

23 - No orçamento de caixa são definidos: (assinale uma ou mais alternativas)

( ) Níveis desejados de caixa ( ) Datas de aplicações e captações de recursos

( ) Prazo médio de recebimento ( ) Prazo médio de pagamento ( ) Outro:

24 - A empresa elabora outros demonstrativos financeiros?

( ) Sim ( ) Não Quais são eles? (assinale uma ou mais alternativas)

( ) Balanço Patrimonial ( ) DRE ( ) Outros: 
Um estudo sobre a organização e o desenvolvimento do processo orçamentário em empresas de tecnologia...

25 - A empresa faz a análise de índices financeiros para avaliação de desempenho organizacional?

( ) Sim ( ) Não Se sim, quais são eles? (assinale uma ou mais alternativas)

( ) Índice de liquidez ( ) Índice de lucratividade ( ) Índice de endividamento

( ) Grau de alavancagem ( ) TIR ( ) Outros:

26 - A empresa possui um relatório em que são apresentados os valores orçados e os reais?

( ) Sim ( ) Não- (então pule para a questão 28)

27 - A empresa realiza a análise da diferença entre as metas reais e as orçadas?

( ) Sim ( ) Não Se sim, para que período? ( ) Mensal ( ) Trimestral

( ) Semestral ( ) Anual

28 - Os resultados obtidos na realização do orçamento auxiliam o desempenho organizacional?

( ) Sim ( ) Não Se sim, de que forma? (assinale no máximo 2 alternativas)

( ) Tornando mais precisa a tomada de decisão ( ) Tornando mais claros o planejamento e controle ( ) Tornando mais efetivos o alcance das metas ( ) Tornando os funcionários mais comprometidos 